\title{
LOS NUEVOS MOVIMIENTOS SOCIALES EN MÉXICO: EL MOVIMIENTO POR LA PAZ CON JUSTICIA Y DIGNIDAD Y \#YOSOY132 ${ }^{1}$
}

ILÁN BIZBERG

\section{INTRODUCCIÓN}

HAY Un CONSENSO PRÁCTICAMENTE generalizado sobre la idea de que, a pesar de que hubo importantes movimientos sociales en las décadas de 1970 y 1990 (el movimiento de autonomía sindical y el zapatista respectivamente), la sociedad civil ha estado ausente, o muy poco representada, en el proceso de democratización de los años noventa que dio lugar a la salida del PRI de la presidencia de la República. Esta circunstancia tuvo consecuencias muy significativas sobre la vida política de nuestro país y de nuestra democracia al grado de que se ha caracterizado al sistema de partidos políticos mexicanos como una partidocracia, ${ }^{2}$ y a la democracia mexicana como una democracia vacía. ${ }^{3}$ Esta ausencia de la sociedad civil se ha producido por dos causas distintas, una relacionada directamente con la situación específica de México, la otra relacionada

\footnotetext{
${ }^{1}$ Este trabajo fue escrito durante mi estancia como profesor invitado al IRIsso / Universidad de París Dauphine (septiembre de 2013-agosto de 2014) con un apoyo del Conacyt y como investigador invitado al CERI, Sciences Po (diciembre de 2013-junio de 2014).

2 Alberto Aziz, “Acción Nacional: el partido en el poder, 2000-2006”, en Ilán Bizberg, México ante el espejo latinoamericano, México, El Colegio de México/Fundación Konrad Adenauer (KAs), 2010.

${ }^{3}$ Ilán Bizberg, "La democracia vacía", en Ilán Bizberg y Francisco Zapata, Los grandes problemas de México, vol. 6: Los movimientos sociales, México, El Colegio de México, 2010.
} 
con la situación que caracteriza a América Latina en general y con algunos de los países centrales. En lo que se refiere a la situación global, en casi todos los países del mundo industrializado y emergente, los actores sociales tradicionales, entre ellos el principal, el sindicalismo, han perdido su centralidad. En los países más desarrollados, esto se ha producido por un proceso de desindustrialización y de tercerización de la economía, mientras que en los países emergentes de América Latina ha sido la consecuencia de la liberalización de sus economías y de un proceso de informalización del empleo. En el caso mexicano, este proceso general se ha acompañado del incremento de los sindicatos de protección ${ }^{4}$ que han ayudado a reforzar la precariedad del empleo y de los bajos niveles salariales y de protección social sobre los cuales se basa el modelo económico exportador con bajo nivel de integración vertical de la industria nacional que en otro estudio hemos denominado de "subcontratación internacional". ${ }^{5}$

La democracia mexicana ha sido descrita como una partidocracia, principalmente porque los partidos están desvinculados de la sociedad debido a que las mediaciones sociales, las organizaciones de la sociedad civil que vinculan a la sociedad política con la población, son muy débiles. Más recientemente, lo que ha caracterizado la vida del país ha sido la trágica guerra contra el narcotráfico, que ha causado miles de muertes, desaparecidos y desplazados, y que, además, ha "contaminado" la delincuencia en México, haciendo que delitos menos graves sean cada vez más violentos y que la lucha entre las bandas sea cada vez más cruel. Esta situación ha conducido a una degradación de la seguridad en México, ha causado múltiples víctimas "colaterales", así como asesinatos de periodistas y de líderes sociales. ${ }^{6}$ Finalmente, como han constatado

${ }^{4}$ Graciela Bensusán y Kevin Middlebrook, Sindicatos y política en México: cambios, continuidades y contradicciones, México, Flacso México-Uam Xochimilco, 2013.

${ }^{5}$ Ilán Bizberg (coord.), Las variedades del capitalismo en América Latina, México, El Colegio de México, en prensa.

${ }^{6}$ México es considerado uno de los países más peligrosos del mundo para ejercer el periodismo, con un saldo de 74 asesinatos de 2006-2012. Cory Molzahn, Octavio Rodríguez Ferreira y David A. Shirk, Drug Violence in Mexico Data and Analysis Through 2012, Trans-Border Institute, University of San Diego, 2013, http://jus- 
diversas organizaciones de derechos humanos, el recurso del ejército para cumplir tareas de seguridad interna ha ocasionado innumerables abusos contra los derechos humanos.

\section{De la teoría de LA MOVILIZACión De RECuRsos A LA DEL SIGNIFICADO DE LA ACCIÓN}

La situación descrita en la introducción ha sido, en buena parte, resultado de la pérdida de centralidad de los actores sociales tradicionales que formaban la base del sistema político mexicano posrevolucionario (además del sindicalismo, las organizaciones campesinas y populares). A pesar de que no han surgido actores con una fuerza equivalente para sustituirlos, han emergido movimientos sociales muy significativos. Para entender la importancia de los nuevos movimientos sociales que analizaremos en este artículo es necesario alejarse de la interpretación dominante en la mayoría de los estudios sociológicos actuales, que se ubican en la perspectiva de movilización de recursos de Charles Tilly, según la cual se analizan los movimientos sociales en función de su capacidad para influir en el sistema de poder de una sociedad. Este autor examina los movimientos sociales desde la perspectiva de sus estrategias para aprovechar las oportunidades para imponer su poder o influencia sobre el gobierno. Analiza los movimientos en función de su capacidad de consolidarse internamente y de los recursos que utilizan para ello y para influir en el sistema político. Distingue el carácter de los movimientos sociales en función de si son competitivos, reactivos o proactivos, aunque no analiza el sentido, el significado, de su acción. En esa medida, aunque la perspectiva de la movilización de recursos se interesa por momentos en la construcción de la identidad de los actores sociales, lo hace sólo para conocer su fortaleza y los recursos que utiliza para construirla; de tal manera aborda sobre todo la cara externa de los movimientos. ${ }^{7}$

ticeinmexico.files.wordpress.com/2013/02/130206-dvm-2013-final.pdf, 15 de abril de 2014.

${ }^{7}$ Charles Tilly, From Mobilization to Revolution, Nueva York, Random House, 
Por el contrario, en este artículo defendemos la idea de que a pesar de que es importante analizar la capacidad de los movimientos sociales para impactar sobre el sistema político, es prioritario estudiarlos en función del sentido que ellos mismos otorgan a su acción (por así decirlo, su cara interna), como hace la escuela accionalista de Alain Touraine. ${ }^{8}$ Desde esta perspectiva, movimientos que parecen poco importantes, si se los mira con base en su impacto político inmediato, pueden estar fuertemente cargados de un sentido ético, el cual puede (o no) tener una mayor influencia en el futuro, o en un lugar distinto al de su surgimiento. Yvon le Bot ha hecho alusión en este sentido al puñado de disidentes que existía en la Unión Soviética y que, si bien no derrotaron al comunismo (que fue transformado por la acción -e inacción- del gobierno de Gorbachov y por el impacto de los movimientos que se dieron en los países satélites de la URSS, en especial de Solidarnosc en Polonia), anticiparon, con su defensa de la libertad individual y su rechazo al dominio del partido comunista de todas la esferas de la vida, la pérdida de legitimidad del sistema comunista, que finalmente provocó su colapso.

De manera similar, aunque el surgimiento del EzLN no tuvo un impacto directo sobre la democratización del sistema político mexicano, ${ }^{9}$ dejó una huella cultural muy significativa sobre la sociedad mexicana e internacional por el contenido ético de su mensaje: modificó en primer lugar la manera en la que los indígenas se conciben y se reivindican a sí mismos, así como la forma en la que el resto de los mexicanos percibía a los indígenas. ${ }^{10}$ Por

1978. La investigación de Ana Elda Palacios Canudas (“\#YoSoy132: desarrollo y permanencia: perspectivas desde la zona metropolitana”, tesis de Maestría en Ciencia Política, México, El Colegio de México, agosto de 2013) es el trabajo más completo desde esta perspectiva.

${ }^{8}$ Alain Touraine, La Voix et le Regard: sociologie des mouvements sociaux, París, Seuil, 1978.

${ }^{9}$ A pesar de que se puede defender la idea de que (junto con el asesinato de Colosio) fue un importante catalizador de la reforma al IFE de 1995 que dio lugar a la ciudadanización completa de este organismo.

${ }^{10}$ Yvon Le Bot y Subcomandante Marcos, Le rềue zapatiste, París, Seuil, 1997; Olivia Gall, "Identidad, exclusión y racismo: reflexiones teóricas y sobre México", Revista Mexicana de Sociología, año 66, núm. 2, abril-junio de 2004, http:/ /www. ejournal.unam.mx/rms/2004-2/RMS04201.pdf, 15 de abril de 2014. 
otra parte, el EZLN tuvo un gran impacto mundial, sobre el movimiento alter-mundialista, al grado de que éste lo considera como su punto de arranque. ${ }^{11}$ Para Yvon le Bot, el zapatismo fue el primer movimiento mexicano ${ }^{12}$ y latinoamericano que, por una parte, se distinguía radicalmente de los movimientos revolucionarios que habían sido dominantes en el continente, que pretendían el poder político y que proponían cambiar todo cuando llegaran a él. Por otra parte, se distingue de los movimientos indígenas y de otros movimientos reivindicativos que pretendían obtener algo del gobierno: tierras, clínicas, caminos, precios justos para sus productos. El zapatismo es el primer movimiento de una nueva era, ya que significa un cambio de paradigma, puesto que ya no pretende el poder del Estado, ni siquiera se dirige al Estado para exigirle algo. Por el contrario, se postula como un movimiento que rechaza la política (tal y como se ejerce actualmente) y que reivindica lo político, entendido como lo público, la cosa pública, la res pública. Asimismo, en ese ámbito erige la reivindicación de la identidad indígena, de la dignidad de ser indígena, el derecho a ser diferente, la autonomía cultural, política y económica, sin rechazar al otro, a los otros, sin siquiera querer separarse de la nación mexicana. En esa medida, explica Le Bot, se vincula a los movimientos alter-globalizadores como el de Seattle y el de los Indignados, entre otros. ${ }^{13}$

Estas características de los movimientos sociales sólo afloran si se los analiza desde la perspectiva del sentido que ellos mismos otorgan a su acción. Es desde esta perspectiva que se analizará el significado de dos movimientos sociales que surgieron durante el sexenio de Felipe Calderón: el de las víctimas de la violencia que azota a nuestro país, el Movimiento por la Paz con Justicia y Dignidad (MPJD), y el de los jóvenes de \#YoSoy132. Ambos movimientos son marginales si se los observa desde la perspectiva de

${ }^{11}$ Geoffrey Pleyers, Alter-globalization: Becoming an Actor in the Global Age, Cambridge, Polity Press, 2010.

${ }^{12}$ Quizá con el de los estudiantes mexicanos de 1968.

${ }^{13}$ Yvon Le Bot, "De la révolution à la mondialisation. Changement de paradigme en Amérique latine", Socio, núm. 2, "Révolutions, contestations, indignations”, París, Éditions de la Maison des Sciences de l’Homme, 2013. 
la movilización de recursos, desde un punto de vista que se focaliza sobre sus objetivos políticos. Mientras que en el caso del primero, logró la muy significativa Ley de Víctimas, no pudo frenar la guerra contra el narco que había iniciado el presidente Calderón y que ha dado lugar a la explosión de violencia en el país. El segundo se expresó en primer lugar por la democratización de los medios de comunicación, la defensa de la libertad de expresión y del derecho a la información y contra la monopolización de estos medios y de su utilización para manipular a la opinión pública; además, demandaron la resolución a la situación de pobreza, desigualdad y violencia que impera en la sociedad mexicana. ${ }^{14}$

\section{LAS TRANSFORMAGiONES DE LOS MOVIMIENTOS EN AMÉRICA LATINA. DE LA TOMA DEL PODER Y LAS DEMANDAS PUNTUALES AL GOBIERNO, A LOS DERECHOS SOCIALES Y SUBJETIVOS}

Durante las últimas tres décadas, América Latina ha transitado por dos transformaciones trascendentes: la democratización general de la mayoría de los países del continente (excepto Cuba) y la globalización. Estos dos fenómenos han tenido efectos contradictorios sobre las sociedades de los diferentes países de la región. En los años ochenta se vivió el retiro de los militares en prácticamente todos los gobiernos latinoamericanos y su regreso a los cuarteles en Argentina, Brasil, Bolivia, Chile, Uruguay y Ecuador, entre otros. En México, la democratización empezó con la reforma electoral de 1977 que legalizó a los partidos de izquierda -el partido comunista entre ellos- como respuesta a las movilizaciones de trabajadores y campesinos de los setenta y a las guerrillas dirigidas por grupos maoístas, comunistas y otras corrientes de izquierda.

Coincidentemente, estos países pasaban por una de las crisis económicas más serias que ha vivido la región y que duró lo suficiente

14 Primer Pliego Petitorio del movimiento, leído en la Estela de Luz, González Villareal, 2010, 117. En cada nueva asamblea iban agregando nuevas demandas en función de los apoyos que recibían de los diferentes grupos sociales que se les unían y que participaban en sus reuniones. 
para que el periodo fuera conocido como "la década perdida", derivando en la mayoría de los países -en menor o mayor grado- en el abandono del modelo económico que habían seguido hasta entonces, basado en la intervención del Estado en la economía, en la orientación hacia el mercado interno, la protección de la industria local y una política social que protegía a los trabajadores de los sectores económicos modernos y del gobierno. El modelo económico de industrialización por sustitución de importaciones fue implementado con base en alianzas nacional-populares que otorgaron un papel central a las organizaciones sociales (principalmente a las obreras), las que trocaban su apoyo político y social al Estado y a sus estrategias económicas por aumentos salariales y de prestaciones y la extensión de las políticas sociales.

En algunos países, los militares rompieron el pacto políticosocial y modificaron el modelo económico desde mediados de los setenta; principalmente por razones políticas (Chile, 1973, Uruguay, 1973, y Argentina, 1976). En otros, el nuevo patrón económico se implementó como respuesta a la crisis de los ochenta (México, 1985). En ambos casos, el nuevo modelo consistió en la apertura de la economía a capitales, tanto productivos, como financieros, en su reorientación hacia las exportaciones en detrimento del mercado interno, el repliegue estatal, la disminución de los trabajadores del Estado y la reducción del alcance y de la extensión de las políticas sociales. La transformación del patrón económico y su reorientación hacia el mercado externo llevó a que la mayor parte de las economías latinoamericanas dependiera de su habilidad para competir en el mercado global y atraer capital extranjero. Esto derivó en una degradación de las condiciones contractuales y laborales por la desregulación y flexibilización de los mercados de trabajo; esta situación exigió minar la fuerza de los sindicatos en aquellos países en los que habían logrado conservarla y donde el gobierno era susceptible de verse presionado por ellos.

Todo lo anterior ha tenido dos consecuencias cruciales en la vida social de América Latina:

La primera es que el principal actor social del periodo de la ISI, el movimiento obrero (junto con otros actores sociopolíticos 
como los campesinos y organizaciones populares urbanas) perdió centralidad a la par de su principal apoyo e interlocutor, el Estado, a pesar de que existen algunas excepciones, por ejemplo en Argentina y Brasil. Cabe mencionar que mientras este actor fue central para la sociedad industrial de los países desarrollados, pues, como lo afirma Touraine ${ }^{15}$ constituía la expresión del conflicto de la sociedad industrial y en ciertos momentos llegó a articular sus intereses particulares con la orientación social y cultural de la sociedad en su conjunto, en el contexto latinoamericano el movimiento obrero fue básicamente un actor político cuya centralidad radicaba en su alianza con el Estado desarrollista. En este continente, el movimiento obrero estuvo generalmente subordinado al Estado y en muchos casos las alianzas eran fomentadas desde arriba y respondían más a los intereses del Estado que a los de los trabajadores, aunque es preciso recordar que en la relación con el Estado corporativo, el sector obrero recibía beneficios a cambio de su fidelidad, lo que significaba una especie de alianza política. ${ }^{16}$

La segunda consecuencia es que el declive del principal actor del siglo xx en América Latina se vio acompañado por la creciente importancia de los sectores pobres de la población que se convirtieron en el foco de las políticas públicas y sociales de los gobiernos por su creciente peso político y electoral. Esto se tradujo, además, en la concentración de las políticas sociales en manos del Estado, en la transición de una política social corporativa orientada hacia el sector obrero, controlada o negociada entre sindicatos y gobiernos, hacia otra focalizada y asistencialista. Este proceso se extendió hacia los sectores de la educación y la salud, cuyos programas se descentralizaron y quedaron bajo jurisdicción local (estatal o municipal), lo que generalmente agravó las disparidades territoriales y sectoriales que se encuentran ahora, por ejemplo, en el centro de las luchas de la juventud chilena por una reforma al modelo educativo de ese país.

${ }^{15}$ Alain Touraine, La production de la société, París, Éditions du Seuil, 1973.

${ }^{16}$ Ilán Bizberg, El Estado y el sindicalismo en México, México, El Colegio de México, 1982; Graciela Bensusán y Kevin Middlebrook, op. cit. 
Frente al debilitamiento del sindicalismo y al surgimiento del sector desestructurado de los pobres, hacia el cual el Estado dirigió sus esfuerzos clientelares, surgen nuevas acciones y movimientos sociales en América Latina, entre los cuales se encuentran los movimientos de derechos humanos en Argentina, el de jóvenes chilenos y los dos mexicanos de los que se trata en este artículo, que comparten ciertas características radicalmente innovadoras:

1) En primer lugar, se crearon desde abajo y no desde la esfera política, por lo tanto su orientación es más social y cultural que política. Aun a pesar de que en muchos países de América Latina existió un movimiento obrero independiente del poder a inicios del siglo xx, que compartía una ideología y una práctica anarcosindicalista y luego comunista, en los años posteriores a la crisis del 29 y a partir del inicio del modelo de sustitución de importaciones, tal movimiento fue reemplazado por un sindicalismo muy cercano al poder, ${ }^{17}$ en muchas ocasiones incluso creado o estimulado desde arriba.

2) Frente a este tipo de sindicalismo híper-politizado, dependiente del poder y de los partidos políticos, los nuevos movimientos sociales comparten un carácter que tanto Touraine como Arato han identificado en los movimientos sociales que llevaron al fin del comunismo en Europa Central y del Este, y que definen como auto-limitado, refiriéndose a que no pretenden adquirir poder político, ni influir en él, ni tampoco vincularse con los partidos o con el Estado, hasta el punto de que algunos de estos movimientos se han definido como anti-políticos. ${ }^{18} \mathrm{Y}$, en efecto, uno de los lemas más recurrentes del movimiento estudiantil en Chile (2011) fue: "el pueblo unido marcha sin partido". ${ }^{19}$

3) No obstante, al igual que los movimientos de Europa central, rechazan la política tal y como se practica en sus países, pero

${ }^{17}$ Francisco Zapata, El sindicalismo latinoamericano, México, El Colegio de México, 2013.

18 Alain Touraine, François Dubet, Michel Wieviorka y Jan Strzelecki, Solidarité, París, Fayard, 1982. Andrew Arato, Civil Society, Constitution, and Legitimacy, Maryland, Rowman and Littlefield Publishers, 2000.

${ }^{19}$ Frase que hace alusión al lema de la Unidad Popular: "El pueblo unido jamás será vencido". 
no lo político, entendido como lo público, la cosa pública. Son en esa medida fundamentalmente políticos, como se vio en el hecho de que contribuyeron de manera fundamental a la democratización de los países comunistas al deslegitimar el poder de los partidos comunistas. De la misma manera, los nuevos movimientos apuntan hacia la profundización de la democracia, reivindicando la democracia participativa frente a la democracia representativa.

A pesar de que muchos autores consideran que los nuevos movimientos surgidos en el actual contexto democrático y globalizado de América Latina están orientados principalmente hacia los excesos del neoliberalismo ${ }^{20}$ y de que en muchos casos se han concentrado en subrayar agravios sociales y económicos particulares, los movimientos más notables de este tipo han "instrumentalizado" acciones en contra del neoliberalismo para denunciar los límites de la democracia y de la ciudadanía liberal, exigiendo su profundización por medio de diferentes formas de participación. Pretenden otro tipo de democracia, en contraste con la puramente liberal, representativa, vertical, para exigir y ejercer (como los indignados españoles, Occupy Wall Street y el MPJD y el \#YoSoy132 mexicanos) una democracia participativa, horizontal.

4) Otra característica fundamental de estas acciones, relacionada con lo anterior, es que tienden a afirmar un nuevo tipo de ciudadanía que rechaza el clientelismo y que por ello no pretende ejercer presión sobre el Estado para obtener concesiones; no pretenden obtener algo puntual y específico por parte del Estado o participar del poder, como lo hacían las acciones tradicionales que reivindicaban tierra, vivienda, subsidios, inversión en infraestructura económica o social, etc. Los movimientos actuales demandan derechos más que concesiones. ${ }^{21}$ Reivindican derechos: humanos (seguridad, Estado de derecho), sociales (trabajo, educación y salud), culturales

${ }^{20}$ Eduardo Silva, Challenging Neoliberalism in Latin America, Cambridge, Cambridge University Press, 2009.

${ }^{21}$ Catalina Smulovitz, "Organizaciones que invocan derechos, sociedad civil y representación en la Argentina”, en Bernardo Sorj y Darcy de Oliveira, Sociedad civil y democracia en América Latina: crisis y reinvención de la política, Río de Janeiro, Ediciones Centro Edelstein, 2007, pp. 13-62. 
(étnicos o religiosos) y subjetivos (divorcio, aborto y matrimonio entre personas del mismo sexo).

5) Finalmente, lo que está en juego en su acción también es radicalmente distinto. No se trata de intereses que puedan definirse de manera individualista-utilitarista, sino que lo que reivindican apunta hacia el sujeto mismo, hacia la capacidad de ser sujeto; en cierta medida demandan el derecho y el ejercicio de la subjetividad humana, como lo muestra el énfasis de todos estos movimientos sobre derechos subjetivos, de un sujeto con derechos políticos, sociales y humanos. Frente a una sociología del individualismo que ha defendido la idea de que lo que caracteriza al mundo moderno es el alejamiento de los meta-discursos, ya sean religiosos o políticos, y que encierra cada vez más al individuo en sus intereses particulares, alejándolo de lo común, de lo público, de lo social, el pensamiento de Amartya Sen y la sociología del sujeto de Touraine proponen lo contrario.

Defienden lo que, en palabras de Amartya Sen, distingue a un sujeto de un individuo. Este autor propone que mientras que el individuo (utilitario) está definido por el deseo de libertad negativa, de perseguir sus intereses sin tener que involucrarse en lo público (como pensaba Constant cuando caracterizaba la libertad de los modernos frente a la libertad de los antiguos), el sujeto se define con base en la libertad positiva, que tiene un contenido, básicamente el derecho a ejercer efectivamente la libertad con toda autonomía. Al contrario de la libertad negativa que se postula frente al Estado, la posibilidad de ejercer efectivamente la libertad individual (o personal) exige que haya garantías públicas, ya endosadas por organizaciones sociales, ya por el propio Estado. ${ }^{22} \mathrm{Si}$ bien Sen no se adentra en analizar la manera en la cual se consigue que el ámbito público garantice la posibilidad de los individuos a ejercer efectivamente su libertad, esto es el interés principal de la sociología del sujeto de Touraine. ${ }^{23}$ Esta sociología propone que la gran

22 Amartya Sen, L'économie est une science morale, París, La Découverte, 2003.

${ }^{23}$ Alain Touraine, La Fin des Sociétés, París, Seuil, 2013; Yvon Le Bot, "De la révolution à la mondialisation. Changement de paradigme en Amérique latine", Socio, núm. 2, "Révolutions, contestations, indignations", París, Éditions de la Maison des Sciences de l'Homme, 2013; Antimo Luigi Farro, "A New Era for Collective 
transformación social de la época contemporánea es el surgimiento de movimientos colectivos orientados por el proyecto de garantizar la plena autonomía del sujeto, la cual se define por la posibilidad de los individuos a decidir sobre las cuestiones fundamentales que lo definen como sujeto: la procreación, la vida en pareja, la relación con los hijos, la sexualidad, la enfermedad y la muerte.

Esto es central, en principio, para las acciones más limitadas, aquellas que ejercen las organizaciones no gubernamentales que se dedican a auxiliar a los individuos marginados, que se ocupan de permitirles ser sujetos autónomos al cuidar de su alimentación, educación, salud, por ejemplo. También para los movimientos de derechos humanos que reivindican la vida misma, la dignidad del ser humano, y también para los movimientos alter-mundialistas o los movimientos de indignados que ponen en el centro de la vida política y de las demandas sociales el derecho de los individuos a expresarse libremente y a tomar las decisiones en lo que respecta a sus vidas. Aunque estas demandas no estaban totalmente ausentes en los movimientos tradicionales, como lo prueba el hecho de que el movimiento sindical reivindicaba la autonomía sobre el conocimiento que tenía el obrero de su trabajo y la resistencia a la centralización de las decisiones y del saber qué concernía su trabajo, en los movimientos actuales esta reivindicación es totalmente central, como puede verse claramente en el caso de los movimientos feminista, pro-divorcio, a favor del aborto, del matrimonio entre personas del mismo sexo, de la eutanasia, etc.

6) Por otra parte, a pesar de que están territorializados, ubicados en un espacio determinado, una región, una plaza, un parque, están des-territorializados en tanto que reivindican conflictos que rebasan cualquier territorio, nación, país y se refieren a los problemas que afectan al mundo actual de la globalización tales como la situación ecológica, el incremento de la violencia, la dominación de las finanzas sobre la producción, el sobre-consumo, la

\footnotetext{
Movements: The Subjectivization of Collective Action”, en Antimo L. Farro y Henri Lustiger-Thaler (eds.), Reimagining Social Movements: From Collectives to Individuals, Surrey, Ashgate, 2014.
} 
situación de los migrantes, de los indígenas, los desempleados, del poder de los medios de comunicación, entre otros. ${ }^{24}$

Por todo ello, pueden calificarse como nuevos movimientos sociales, aunque a su vez se distinguen de los llamados nuevos movimientos sociales de los que se hablaba en las décadas de 1970 y 1980: los movimientos feminista y nuclear. Con todo, comparten estos nuevos movimientos la centralidad del individuo, su subjetividad, su visión ética del mundo, de la economía y de la política. ${ }^{25}$

\section{Los Nuevos MOvimientos SOCiales EN MÉXico}

En este contexto se ubican los dos movimientos sociales que surgen en el sexenio de 2006 a 2012. Por una parte, el Movimiento por la Paz con Justicia y Dignidad se forma frente a la tragedia humana en la que se convirtió la "lucha contra las drogas" lanzada por el último gobierno panista y que continúa mas calladamente en el sexenio actual. Por la otra, el movimiento \#YoSoy132 surge de la coyuntura de la visita del candidato a la presidencia del PRI a la Universidad Iberoamericana. Dicho movimiento albergaba un profundo malestar de la juventud mexicana con el sistema político y con la situación del país, mismo que se ha vuelto a expresar en el movimiento del Politécnico Nacional y de los maestros rurales en 2014.

Ante el auge de la violencia en varios países de América Latina, han aparecido numerosos movimientos que exigen las garantías mínimas de protección que debe garantizar cualquier Estado. En muchas ocasiones, este tipo de acciones han sido detonadas por un crimen atroz, como fue el caso de Axel Blumberg en Argentina en 2004, el del hijo de Alejandro Martí en 2009, y el del más reciente asesinato de varios jóvenes, entre ellos el hijo de Javier Sicilia, un renombrado poeta mexicano. En México, desde 2004 se han producido varias de estas manifestaciones puntuales,

${ }^{24}$ Yvon Le Bot, "De la révolution à la mondialisation. Changement de paradigme en Amérique latine“, Socio, núm. 2, "Révolutions, contestations, indignations", París, Éditions de la Maison des Sciences de l'Homme, 2013.

${ }^{25}$ Alain Touraine, La Fin des Sociétés, París, Éditions du Seuil, 2013. 
que no han perdurado. El primer movimiento de que nos ocupamos en este artículo, el Movimiento por la Paz con Justicia y Dignidad (MPJD), surgido en 2010 a raíz del asesinato del hijo de Javier Sicilia junto con otras seis personas en Cuernavaca, nace de manera espontánea mediante un llamado por parte del poeta para reunirse a la salida de dicha ciudad e iniciar una caravana hacia la ciudad de México para exigir al gobierno un cambio de estrategia. La caminata duró varios días y aunque tuvo poco seguimiento en los medios, los testimonios de las víctimas "colaterales" a la guerra que se le fueron sumando en el trayecto y que levantaron la voz para narrar por primera vez su caso tuvieron tanto impacto en la opinión pública, que, al llegar al Zócalo, una multitud de varios miles de personas la esperaba. Después de esta manifestación inicial del movimiento, se realizó una nueva caravana hacia el sur, otra hacia el norte y una última a los Estados Unidos. En todas se dio la palabra a las víctimas, que fueron atendidas por un número cada vez mayor de personas en la medida en que los medios se vieron forzados a dar cada vez mayor cabida a este movimiento.

El MPJD se distingue de las movilizaciones anteriores de varias formas: por su autenticidad y valor ético, su significado y su capacidad de perdurar. Aunque las manifestaciones de 2004, 2005 y 2008 reflejaron una preocupación legítima de varios sectores de la sociedad civil y consiguieron reunir a varios cientos de miles de personas de todas las clases sociales, fueron organizadas por asociaciones establecidas y en su mayoría cercanas al "establishment" político o empresarial, ${ }^{26}$ lo que les valió la mediatización por parte de Televisa y Tv Azteca. Como es costumbre en todos los mítines políticos, en dichas manifestaciones eran los líderes de las diferentes organizaciones los que tomaban la palabra, mientras que las víctimas permanecían calladas. El MPJD fue el primero que dio a las víctimas la palabra; muchos mexicanos quedamos estupefactos.

Este movimiento provocó la toma de conciencia sobre los efectos perversos de la "guerra contra las drogas" en términos de

${ }^{26}$ Entre los organizadores se encontraban incluso asociaciones contra el aborto que hacían una amalgama de temas entre la seguridad ciudadana y los derechos del feto. 
la explosión de la violencia, las "víctimas colaterales" y los abusos contra los derechos humanos por parte del ejército y la policía. Al igual que sucedió con el EzLN, la autenticidad del movimiento despertó la empatía de la opinión pública y, tal vez temporalmente, también la de algunos actores políticos. Así como el movimiento indígena despertó las conciencias de la sociedad mexicana frente a un problema ignorado o que se pretendía ignorar -el de la marginación y el racismo crónico contra los indígenas mexicanos-, el MPJD despertó la conciencia de que las muertes violentas que el gobierno de Calderón asignaba a una lucha entre carteles de la droga implicaba a mucha gente inocente y demostraba su fracaso.

El movimiento \#YoSoy132 fue un punto de quiebre en la campaña de las elecciones presidenciales en las que, a pesar de que no modifican su resultado, hacen emerger toda una serie de problemas fundamentales de la sociedad mexicana que estaban oscurecidas por las campañas de los partidos y que empujan a la sociedad a discutirlos. ${ }^{27}$ La coyuntura en la que surge es la de la visita del candidato Peña Nieto a la Universidad Iberoamericana, durante la cual una manifestación en su contra lo obligó a abandonar apresuradamente el recinto. Los responsables de campaña del PRI, Televisa, TV Azteca y varios medios escritos difundieron información que pretendía hacer creer que las manifestaciones habían sido organizadas por militantes del PRD. Esta afirmación fue desmentida por los estudiantes mediante un video subido a la red en el que 131 estudiantes mostraban sus credenciales universitarias e invitaban a otros a unirse a la iniciativa, razón por la cual tomó el nombre de \#YoSoy132.

Este movimiento nace como una manifestación en contra de la manipulación de la información en el caso específico de los acontecimientos de la Univrsidad Iberoamericana, no obstante, en el fondo se cuestionaba a los medios sobre su capacidad para imponer las representaciones culturales que vehiculan y en gran medida generan. Es por ello que desde los primeros momentos

27 Jorge Alonso, "Cómo escapar de la cárcel de lo electoral: el Movimiento \#YoSoy132”, Desacatos, núm. 42, mayo-agosto de 2013, pp. 17-40. 
del movimiento la democratización de los medios de comunicación surgió como la demanda principal. ${ }^{28}$

Vamos enseguida a analizar estos dos movimientos con base en su significado y la manera en la que definen ellos mismos su identidad, contra quién están luchando, sus métodos de lucha, sus formas de organización y su propósito principal.

\section{Identidad y oposición}

El Movimiento por la Paz con Justicia y Dignidad es una acción de las víctimas de la ola de violencia que ha azotado a México desde que el presidente Calderón lanzó una guerra frontal contra el narcotráfico utilizando para ello al ejército. En esa medida, su sentido de pertenencia es muy claro y se distingue de los movimientos anteriores en contra de la inseguridad que agrupaban tanto a víctimas de la violencia, como a una ciudadanía cada vez más temerosa de la creciente inseguridad que domina en el país. Mientras que estos últimos movimientos, que se dieron en 2004 y 2005, y de nuevo en 2008, demandaban mayor fuerza y eficacia por parte del Estado para combatir el crimen organizado o no, el MPJD expresa, por el contrario, una crítica de las políticas represivas basadas en la acción del ejército y exige soluciones alternativas multidimensionales (económicas, sociales y políticas) al problema de la violencia. Pero, sobre todo, ante la explosión del número de muertes no aclaradas, de desapariciones, de abusos a los derechos humanos por parte de las fuerzas estatales y de los grupos criminales, así como de la explosión de la violencia surgida a raíz de la "guerra contra las drogas", el MPJD exige el derecho a conocer los detalles de cada una de estas muertes, el regreso de los desaparecidos, el castigo a los agentes del gobierno que cometieron abusos de los derechos humanos; en suma, dejar de tratar a los caídos por la violencia, sean éstos criminales o víctimas, como simples estadísticas, actitud

${ }^{28}$ Roberto González Villareal, El Acontecimiento \#YoSoy132. Crónica de la Multitud, México, Terracota, 2010. También: Gloria Muñoz Ramírez, \#YoSoy132 Voces del Movimiento, México, Ediciones Bola de Cristal, 2013. 
que sólo fomenta la impunidad al restar valor a la vida humana y a la dignidad que cada una de las personas merece.

Las víctimas han estado desde el principio del Movimiento, la lucha de varias de ellas antecede por mucho la conformación del mismo y está caracterizada por la incansable búsqueda de espacios para exigir justicia, verdad y la presentación con vida de los desaparecidos. Antes del nacimiento de este espacio ellas ya habían tocado mil puertas, algunas de ellas muy conocidas, siendo rechazadas una y otra vez. Cuando Javier [Sicilia] comenzó a declarar públicamente exigiendo justicia por la muerte de su hijo y por las miles de víctimas de la guerra que vive nuestro país, muchas de ellas se identificaron no sólo con su discurso sino con la integridad moral del personaje. Decidieron caminar junto a él primero en Cuernavaca, luego rumbo a la ciudad de México y después por norte y sur del país encontrándose y uniéndose a las voces de más y más víctimas de esta guerra. Como ellas y ellos no han dejado de participar sino que han sabido solidarizarse con otras y recibir en todo momento a quienes siguen llegando en una dinámica que lamentablemente también da muestra de la magnitud de la situación que se vive en el país y de la incapacidad que ha habido para detenerla. ${ }^{29}$

El movimiento \#YoSoy132 es una labor de jóvenes a los que unen distintas formas de pertenencia, que se ubican en una situación de crisis internacional, económica y ecológica, así como una crisis política, social y humanitaria inédita por la que está pasando el país desde 2006. Se asemeja en esto a los movimientos de los Indignados, Occupy Wall Street, el de la Plaza Tahrir o Gazi, los cuales agrupan muchas demandas insatisfechas, frustraciones y agravios relativos al desempleo, la educación y el funcionamiento del sistema político y económico.

En primer lugar, en México, como en muchos otros países del mundo que vieron surgir los movimientos recientes (en Túnez, Egipto, Turquía, España, Estados Unidos e Israel), y como se expresa

29 Alberto M. Solís Castro, "Corazón de movimiento", Brújula Ciudadana, núm. 34, junio de 2012. 
asimismo en los movimientos alter-mundialistas, los jóvenes se enfrentan, en contraste con las generaciones que los antecedieron, a una situación en la cual sus expectativas de vida son peores que las que vivieron sus padres. Están enfrentados a la precarización e inseguridad laboral que ha significado la globalización de la economía y la actual crisis económica global, que han agravado el desempleo y ensanchando el empleo precario. Enfrentan, además, una crisis ecológica global, de la cual se tiene cada vez más conciencia y que implicará un menor ritmo de crecimiento económico o la destrucción del ecosistema. En el caso específicamente mexicano, la explosión de violencia que se dio en el sexenio Calderón les impide llevar a cabo una vida normal: pasear, divertirse, viajar por el país. Finalmente, los jóvenes son una generación que no conoció la vida bajo dominio del PRI, que no tuvo la experiencia de la democratización de los años ochenta y noventa, sino que ha llegado a la madurez en una democracia imperfecta.

Este cambio generacional es indispensable para entender por qué los jóvenes chilenos se manifiestan en contra de Bachelet, un gobierno del partido socialista en una coalición con el partido demócrata cristiano (la Concertación), sin consideración por el partido que llevó a Allende al poder y sin el temor de la generación pasada que vivió el golpe militar, de agudizar la contradicciones que se han interpretado como uno de los factores que dieron lugar al golpe de Pinochet. También es central para entender por qué los jóvenes de Brasil se enfrentan a un gobierno del PT, sin considerar la épica lucha de ese partido obrero por la democratización y por llegar al gobierno, y, por el contrario, lo estimen parte del establishment político, a lo que no ayuda, por otro lado, el involucramiento de este partido en el caso más sonado de corrupción de los últimos años: el del mensalao.

Por una parte, el Movimiento por la Paz con Justicia y Dignidad está claramente formado por víctimas de la violencia que se han unido para dar un sentido a sus vidas luego de la tragedia de haber perdido a un ser querido o de tenerlo desaparecido, y que luchan para que el gobierno reconozca su situación de víctimas, investigue la manera en la que sus familiares fueron asesinados y castigue a los culpables o encuentre a sus familiares desparecidos. 
Por la otra parte, el movimiento \#YoSoy132 es mucho más heterogéneo; agrupa a estudiantes de universidades privadas y públicas, así como a jóvenes que no pueden encontrar lugar en el sistema universitario del país, a otros que protestan por la falta de oportunidades que ofrece un modelo económico que crea pocos empleos y aún menos empleos de calidad, así como a otros que protestan en contra de abusos e injusticias de diversos tipos. De esta misma manera, los indignados españoles congregaron a distintos sectores de la población en torno a la desigualdad creciente en Europa y ante la injustica de tener que pagar (con el desempleo, la baja de nivel de vida) los efectos de una crisis causada por los manejos especulativos del capital financiero. Asimismo los jóvenes/estudiantes chilenos están unidos por el sentimiento de injusticia que significa un modelo educativo (y en general el económico) que los obliga a endeudarse (a ellos y a sus familias) para poder estudiar.

En el caso más específico del movimiento \#YoSoy132, la identidad coyuntural estuvo definida, como ya lo mencionamos, por el intento por parte del PRI y de las televisoras que apoyaban al candidato para hacer presentar los sucesos que acompañaron a la visita de Peña Nieto a la Universidad Iberoamericana como una acción concertada de militantes favorables a López Obrador. No obstante, el movimiento pronto se extendió real y simbólicamente:

el Movimiento 132 somos nosotros, somos la demostración de la indignación y la rabia de los niños muertos en la guardería ABC, somos Wirikuta, somos Cherán en Michoacán, somos Copala, somos los rarámuris muertos, somos la indignación ante la brutal fuerza del Estado, somos la indignación ante la guerra contra el narcotráfico y sus más de setenta mil muertos. Toda esta historia somos nosotros, justicia pedimos!, justicia pedimos! Porque éste es nuestro movimiento y vamos a luchar por ella hasta que se haga justicia, justicia!, justicia! Toda esta historia hoy la reivindicamos y la revivimos, la revivimos en el vendaval de este movimiento, hoy decidimos y decimos ser 132, ser historia y ser la conciencia mexicana, no olvidamos y gritaremos desde nuestra conciencia, hoy y siempre: somos $132 .{ }^{30}$

${ }^{30}$ Citado en Ana Elda Palacios Canudas, “\#YoSoy132: desarrollo y permanen- 
Estos movimientos tienen a su vez distintos adversarios. En el caso de los Indignados se trata del capital financiero y de los políticos que acordaron salvarlo a costa del bienestar de las poblaciones locales; en el de los estudiantes chilenos, se trata de los distintos gobiernos que han abrazado el modelo neoliberal y que no se han atrevido a modificarlo. En el caso del \#YoSoy132, son las empresas de comunicación masiva "que no fueron elegidos por nadie, no tienen ninguna investidura democrática y deciden sobre cosas fundamentales de la vida de todos [...] el bicéfalo monstruoso contra el que nos enfrentamos: Televisa y TV Azteca". ${ }^{31}$

El MPJD se enfrenta al gobierno y al sistema político que ha llevado a la guerra contra el narco, y a un Estado que no puede proteger y que comete abusos contra su población, que permite la impunidad y que no reconoce a las víctimas que ocasiona esta situación.

Como lo plantea Javier Sicilia, el MPJD rechaza

La misma lógica del calderonismo: el Estado que vive para sí, que administra la violencia, que reduce todo a un asunto policiaco donde sólo cuentan el combate y el control. Hay que volver al otro inofensivo, hay que transformarlo de nuevo en objeto controlado y reducido a estadística. Las víctimas no existen.

Esta óptica, ciertamente, produce una percepción de seguridad al Estado. Sin embargo, en la realidad, genera una violencia mayor. Toda desmemoria, todo olvido del otro, conduce -es una lección de la historia- a repetir y a ahondar el horror. Un país que no se reconcilia con sus víctimas, que insiste, como los criminales, en borrarlas del mundo, está destinado a una interminable barbarie, a una aceptación sin límites de la violencia. ${ }^{32}$

cia: perspectivas desde la zona metropolitana”, tesis de Maestría en Ciencia Política, México, El Colegio de México, agosto de 2013.

31 Ana Elda Palacios Canudas, entrevista a un estudiante de ciencia política en la UAMI-I en su tesis.

32 Javier Sicilia, "Las víctimas", Proceso, 31 de marzo de 2014 en http://movimientoporlapaz.mx/articulos-y-reportajes/, 14 de abril de 2014. 
Por la profundización (participativa) de la democracia

Ambos movimientos se definen claramente con base en un rechazo a la política tal y como se hace en nuestro país, y en la recuperación de lo político: el espacio público para los individuos y los movimientos sociales. No obstante, su identidad se construye no sólo por lo que rechazan, sino por lo que buscan en su lucha. El Movimiento por la Paz con Justicia y Dignidad plantea que la inoperancia del modelo económico, pero en especial la ineficiencia de los sistemas judiciales y la corrupción de las fuerzas policiacas, están en la raíz de la violencia que se ha diseminado en el país. De manera similar, para los jóvenes mexicanos de la segunda década del siglo xxI, el regreso de un partido de Estado mediante una campaña simulada en los medios masivos de comunicación que permite la concentración de estos medios es una falla fundamental de la democracia mexicana.

Ambos son movimientos alejados de la idea de la toma del poder o de una definición de su carácter en función de sus exigencias al poder instalado, al gobierno. Por esta razón, ambos marcan claramente sus distancias con respecto al poder:

Seguimos estando hasta la madre de ustedes, políticos, gobiernos, partidos y candidatos, porque la corrupción que han dejado instalarse en las instituciones es cómplice de todos estos crímenes y de todo este dolor $-98 \%$ de impunidad quiere decir que los criminales están también dentro del Estado [...] nos negaron la Reforma Política y la Reforma de los Medios de Comunicación, que exigimos en el punto 6 del pacto y que habría podido blindar las elecciones; porque ignorando la emergencia nacional, el clamor de las víctimas, la balcanización del país y la necesidad de la paz, no construyeron un gobierno de unidad nacional y se han lanzado a una campaña política donde sus mezquinos pleitos por el poder, sus desagradables rostros con que llenan nuestras calles, sus inanes eslóganes, sus onerosos dispendios, son la continuación de la guerra por otros medios y la muestra más clara de su lejanía de la realidad del país y su complicidad con el horror -sus elecciones son, en realidad, una cortina de humo con apariencia de democracia, que a lo único que condu- 
cirá es a una nueva y más precaria administración de la desgracia del país. ${ }^{33}$

[...] la otra campaña ${ }^{34}$ [apostaba por la] transformación del país y de una nueva constituyente [...] Yo no voté por AmLo porque yo pensaba que si llegaba al poder iba a cooptar a todo el movimiento social como había pasado en Argentina con Kirchner y los movimientos piqueteros y queríamos mantener la autonomía de izquierdas anticapitalistas $[\ldots]^{35}$

Estos dos movimientos expresan un desencanto con los partidos políticos y con la política, como la que mostraron las movilizaciones en Argentina durante la crisis de 2001, que clamaban “... que se vayan todos". Como las dos olas de movilizaciones estudiantiles en Chile -la de los alumnos de secundaria en 2006 y la de los universitarios en 2011-, que marcan una ruptura fundamental respecto a la acción social tradicional en ese país, que siempre estuvo ligada a los partidos políticos, quienes representaban el conducto principal de la participación política y social en el país. ${ }^{36} \mathrm{Su}$ lema principal transparenta el rechazo a los partidos políticos: "todos unidos contra los partidos". ${ }^{37}$ Los movimientos de Indignados de la plaza del Sol en Madrid, así como los más recientes contra la

${ }^{33}$ Javier Sicilia, "Seguimos hasta la madre”, Brújula Ciudadana, núm. 34, junio de 2012.

${ }^{34}$ Del EzLn, que proponía no participar en las elecciones de 2006.

${ }^{35}$ Entrevista a miembro de la mesa de trabajo sobre democratización de medios del \#YoSoy132.

${ }^{36}$ Manuel Antonio Garretón et al., "Movimiento social, nuevas formas de hacer política y enclaves autoritarios. Los debates del Consejo Asesor para la Educación en el gobierno de Michelle Bachelet en Chile”, Polis, núm. 30, 2009.

37 Con estas movilizaciones, por primera vez en la historia chilena un movimiento social actuó con total autonomía frente a los partidos políticos y, más aún, los rechazó. Estas dos movilizaciones se plantaron en contra de uno de los principales enclaves "sociales" de la dictadura de Pinochet, el sistema educativo, al que los gobiernos de la Concertación habían hecho escasas reformas para concentrarse en los sistemas de pensiones y de salud. Los jóvenes se manifestaron en contra de un modelo educativo en donde las escuelas y universidades, tanto públicas como privadas, cobran altas tarifas y obligan a los estudiantes y a sus familias a contraer préstamos que implican fuertes deudas durante varios años; exigían que la educación fuera considerada un derecho social y no una mercancía. 
corrupción del PT, del sistema político en general y del alza de la vida en Río y São Paulo, también se asemejan. De igual manera, el movimiento de los Indignados, que exclamaban en la Plaza del Sol:

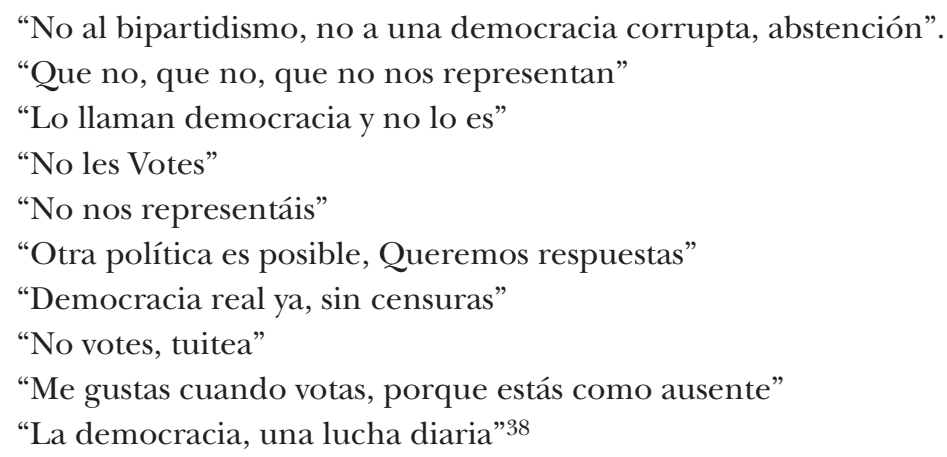

El movimiento \#YoSoy132 se declara apartidista y contra los partidos políticos que existen en México, al tiempo que se define como profundamente político "porque se interesa en los asuntos públicos y pretende desarrollar espacios para la participación ciudadana activa, sin limitar esta responsabilidad a la llamada clase política que pretende ser la única intérprete de los asuntos políticos del país". ${ }^{39}$

Todos estos movimientos tienen su punto de partida en la insatisfacción con los partidos políticos, pero su descontento es aún más profundo, pues se dirige contra la democracia representativa como tal, en la cual los ciudadanos sólo tienen la posibilidad de hacer responsable (accountable) a posteriori, la de castigar, a un funcionario o partido por medio del voto, pero no la de controlar su acción. ${ }^{40}$ Ante esta limitación de la democracia representativa, se exige una democracia participativa.

${ }^{38}$ Véase http: / /www.mi-web.org/miembros/16-tanya/textos/60917-frases-del15-m consultado el 13 de marzo de 2013.

39 \#YoSoy132, "Principios generales del movimiento", 26 de junio de 2012, http:/ / www.yosoy132media.org/yosoy132oficial/principios-generales-del-movimiento/

${ }^{40}$ Guillermo O’Donnell, "Horizontal Accountability in New Democracies", Journal of Democracy (Baltimore, The Jonhs Hopkins University Press), vol. 9, núm. 3, 1998. 
Ambos movimientos exponen la necesidad de recuperar el espacio público para la sociedad civil y crear mecanismos para su expresión:

La democracia y la vida política del país no pueden ser privilegio de una clase política que busca perpetrarse en el poder, los y las ciudadanas requerimos de espacios desde los cuales realmente incidamos en el rumbo de nuestro país. Por ello consideramos necesario impulsar una verdadera reforma política que contemple el mandato revocatorio, las candidaturas ciudadanas y la consulta y el referéndum cómo figuras desde las cuales los y las mexicanas podamos opinar sobre decisiones cruciales del rumbo de México. Lo(a) convocamos a impulsar la democratización de los medios de comunicación, medida que sin duda pasa por poner fin al duopolio televisivo. Al mismo tiempo, lo(a) emplazamos a impulsar y apoyar la creación de medios de comunicación masiva organizados desde la ciudadanía en defensa del interés público. ${ }^{41}$

Tanto las víctimas de la violencia, como los estudiantes, son arrojados hacia el ámbito público por circunstancias no buscadas, pero una vez en él elaboran una concepción propia de lo político que los transforma a ellos mismos y a la acción política en sí:

La mayoría nunca había participado en un movimiento social ni pretendían hacerlo antes de la tragedia que marcó sus vidas. Pero pronto han ido viviendo un proceso de transformación radical que los ha cambiado de ser individuos caracterizados por la injusticia de la que han sido objeto para convertirse en verdaderos promotores de los derechos humanos de todas y todos en nuestro país y en luchadores sociales organizados [...] Pero esto aún no bastaba, era necesario que las propias víctimas tomaran en sus manos la dirección del Movimiento para imprimirle un nuevo ritmo, dinámica y ruta en un momento

${ }^{41}$ Javier Sicilia, "Políticas públicas para construir la Paz. Texto leído a los y la candidata a la Presidencia en los Diálogos por la Paz", 28 de mayo de 2012, en http:/ / movimientoporlapaz.mx/es / 2012/05/29/politicas-publicas-para-construir-la-paz-texto-leido-a-los-y-la-candidata-a-la-presidencia-en-los-dialogos-por-lapaz/ 14 de abril de 2014. 
en que su caminar se percibía lento y disperso frente a la urgencia de quién mantiene como estandarte la esperanza cargando el dolor de la incertidumbre a cada segundo. ${ }^{42}$

En el caso de los estudiantes del \#YoSoy132, esto se refleja en una creación de una organización interna horizontal, en la cual los liderazgos son rotativos:

En el movimiento cuando sale alguien y dice "yo tengo algo que puede salvar la discusión" y lo propone y todo mundo está de acuerdo: eso es un líder. No tiene por qué ser la misma persona siempre, puede haber muchísimos líderes en ciertos movimientos o en ciertos momentos; pueden ser emergentes, pueden ser muy efímeros y sin embargo son liderazgos [...]pensar en cómo estructurarse siendo horizontal $[\ldots]$ pero siendo eficaces $[\ldots]$ cómo logramos no repetir estructuras con las cuales estamos en desacuerdo. ${ }^{43}$

En el caso de los movimientos como el de los Indignados u Ocupa Wall Street esta transformación es muy clara. Se vive otra forma de democracia: una organización de las asambleas con base en formas de participación que ejercen la democracia horizontal, sin liderazgos, sin jerarquías, donde todos los asuntos son susceptibles de ser discutidos. ${ }^{44}$

Varios autores que han descrito estos movimientos en España, Atenas y Nueva York han acentuado el hecho de que llevaron a cabo

una ruptura por su manera abierta, participativa, directamente democrática de organizarse y de funcionar [...] [mediante] procedimientos flexibles y que pueden ser modificados de un día al otro; que son autocriticados y ajustados en función de errores, de comentarios y sugerencias que emergen directamente de su puesta en práctica. [...]

42 Alberto M. Solís Castro, "Corazón de movimiento", Brújula Ciudadana, núm. 34, junio de 2012.

${ }^{43}$ Entrevista a tres estudiantes del IтAм, del \#YoSoy132, 27 de agosto de 2013.

${ }^{44}$ David Graeber, "Faire l'impossible. À propos de la décision au consensus", Revista Contretemps (ed.), D'Athènes à Wall Street, \#indignés! Échos d'une insurrection des consciences, París, Éditions la Découverte, 2012, pp. 97-100. 
Rechaza toda forma de representación o de mediación, que garantiza por la circulación permanente de las posiciones revocables que atraviesan todas las estructuras y todas las funciones nacidas de este movimiento. [...] Este aspecto "sin cara" [...] es la mejor forma para que el movimiento preserve la transparencia de su organización, así como su voluntad de ser la expresión de todo el mundo -y no sólo de su fracción supuestamente más "vanguardista" o más "politizada". ${ }^{45}$

De hecho, estos movimientos utilizan los medios de comunicación como Internet (Twitter en particular) y los teléfonos celulares, porque éstos están mejor adaptados a estas formas de organización horizontal, sin liderazgos, de democracia participativa, continua. "Los dispositivos de tipo red no crean, por supuesto, los movimientos, sino que son los instrumentos adaptados a ellos porque corresponden en parte a las estructuras horizontales, reticulares y a las experimentaciones democráticas de los movimientos mismos". ${ }^{46}$

\section{Por derechos no concesiones}

Como lo hemos mencionado, mientras que las manifestaciones en contra de la inseguridad de la primera década de 2000 reclamaban el fortalecimiento de la política de seguridad del gobierno, el MPJD se centró en la constatación del fracaso de una política enfocada exclusivamente en la seguridad para enfatizar las fuentes sociales de la violencia: la falta de oportunidades para los jóvenes por la magra creación de empleos en el país y por los bajos salarios, la impunidad y corrupción que dominan la esfera política y el aparato de justicia, la falta de respeto por la vida y la dignidad tanto por parte de los narcotraficantes como de las fuerzas de seguridad. Por otra parte, mientras que las manifestaciones contra la

45 Christos Giovanopoulos, "La démocratie est née dans les places", Revista Contretemps (ed.), D’Athènes à Wall Street, \#indignés! Échos d'une insurrection des consciences, París, La Découverte, 2012, pp. 83-84.

${ }^{46}$ Michael Hardt y Toni Negri, "Le combat pour la 'démocratie réelle'”, Revista Contretemps (ed.), D’Athènes à Wall Street, \#indignés! Échos d'une insurrection des consciences, París, Éditions la Découverte, 2012, p. 80. 
inseguridad de la primera década del siglo Xxi se enfocaron en demandas al Estado, el MPJD se centró en las víctimas y, al igual que los nuevos movimientos sociales latinoamericanos, ha demandado derechos: respeto a los derechos humanos, exigencia del derecho a saber cómo fueron asesinados los familiares, conocer el paradero de familiares desaparecidos y el derecho a la justicia por los delitos o abusos cometidos por militares o policías. Es por ello que la principal de sus demandas fue una:

[...] ley de Seguridad Humana y Ciudadana que ponga énfasis en los derechos humanos, en un cambio de estrategia en el combate al crimen, en una limpieza real de los delincuentes que hay en todos los órdenes del gobierno, y en la necesaria construcción de un México donde quepan muchos Méxicos. Sin esa Ley, sin ese énfasis, sin esa limpieza, sin ese cambio, sin esa construcción, trabajados por y con todos, las víctimas seguirán acumulándose y la vida democrática del país quedará destrozada bajo el desprecio de la violencia y el crimen. ${ }^{47}$

El padre Miguel Concha Malo, integrante del MPJD habla en una entrevista de las semejanzas de su movimiento y los que han surgido a raíz de la crisis global de 2008 en términos de derechos:

la identificación y empatía entre los diversos movimientos sociales que están surgiendo a nivel global es debida a que "grupos como los Indignados y los Ocupa quieren rescatar, en primer lugar, su dignidad como personas, sus derechos dentro de un sistema en crisis que les ha dejado de lado por los intereses económicos. Los sujetos que conforman estas luchas se están reivindicando como sujetos de derechos y no objetos mediante el reclamo a los políticos, poderes públicos y gobiernos. Se llaman Indignados porque les han arrebatado su dignidad, se la han pisoteado y privado de sus derechos. ${ }^{48}$

${ }^{47}$ Palabras del MPJD al Ejecutivo por la publicación de la Ley General de Víctimas, leído por Javier Sicilia el 9 de enero 2013.

48 Padre Miguel Concha Malo, citado por Paulina Candia y Marta Molina, "Queremos paz, justicia y dignidad: el ¡ya basta! de un movimiento global”, Brújula Ciudadana, 2012, pp. 40-41. 
De igual manera, el movimiento \#YoSoy132 se expresa no solamente en nombre del rechazo a la manipulación de los medios de comunicación, ni tampoco por la exigencia de la apertura del espectro de las comunicaciones en el país, sino por el derecho a la comunicación, pero aún más fundamentalmente frente a una democracia representativa, el derecho a la protesta y a la acción colectiva.

Somos apartidistas porque sus instituciones no nos representan, pero exigimos respeto a la voluntad popular y afirmamos que existe otra manera de hacer política; reconocemos las limitaciones de su "democracia sexenal" por lo que nuestro horizonte de lucha transciende el escenario electoral. Reivindicamos nuestros derechos de acción colectiva, organización política y reflexión comunitaria, tres momentos de un mismo proceso. ${ }^{49}$

De la misma manera que la democracia directa es reivindicada como derecho, sucede en el manifiesto de Occupy:

A todos los pueblos del mundo. Nosotros, la asamblea general de la ciudad de Nueva York, que ocupa Wall Street en Liberty Square, los convocamos a afirmar su poder. Ejerzan su derecho a reunirse pacíficamente, a ocupar el espacio público, a tomar en sus manos los problemas a los que estamos enfrentados para encontrar soluciones accesibles a todos. ${ }^{50}$

Los derechos a la manifestación, la expresión, la reunión, la democracia directa se conciben como derechos humanos básicos, en el mismo orden de derechos que la vida misma y la seguridad, y que los que atañen "a la alimentación, la salud, laborales, a la migración, a un ambiente saludable, y al acceso a la información". ${ }^{51}$

49 Max Alcántara, "Las antorchas que escupían enojo e irradiaban esperanza”, Revista Hashtag, año 1, núm. 4, mayo-junio de 2013, p. 31.

50 Declaración de la Ocupación de Wall Street, Revista Contretemps (ed.), D’Athènes à Wall Street, \#indignés! Échos d'une insurrection des consciences, París, La Découverte, 2012, p. 73.

${ }^{51}$ Revista Hashtag, año 1, núm. 4, mayo-junio de 2013, varias páginas. 
De igual manera, el segundo punto del manifiesto de los Indignados de la Plaza del Sol exige el respeto de los derechos fundamentales reconocidos por la constitución, tales como: el derecho a una vivienda digna, la salud pública, gratuita y universal, la libre circulación de personas y el fortalecimiento de la educación pública y laica. ${ }^{52}$

\section{Lo-que-está-en-juego: el sujeto, la subjetividad, la libertad positiva}

Una de las características de los nuevos movimientos sociales como el de La Puerta del Sol u Occupy Wall Street es entender que el instalarse en una plaza al lado de Wall Street no va a cambiar al mundo, ni pretenderlo, a diferencia de los movimientos revolucionarios que sí lo creían y pretendían. Se conciben como movimientos que cambian a los individuos en sí mismos, por medio de la participación y por el ejemplo y mensaje que explayan; son, de esa manera, fundamentalmente subjetivos. Además, muchos de sus propósitos se refieren a la subjetividad: la felicidad, el modo de consumo, la sexualidad, el matrimonio, el cuerpo. ${ }^{53}$

Un movimiento como el de Indignados tiene sentido en la medida en que los participantes se encuentran con otras personas, hablan con ellas, ejercen acción colectiva con la que buscan cambiar al mundo transformándose a sí mismos. El movimiento de 1968 ha sido interpretado de esta misma manera: no cambió al mundo aunque modificó profundamente la forma de ver al mundo. A raíz de ese movimiento se transformó radicalmente la manera en la que se relacionaban las parejas, la sexualidad, el vínculo entre los padres y los hijos; fue una gran revolución cultural, al grado de que Wallerstein la concibe como el punto de quiebre de la geocultura que fundamentaba el sistema-mundo contemporáneo. ${ }^{54}$

52 Propuestas de la Asamblea General de Puerta del Sol, en Revista Contretemps (ed.), D’Athènes à Wall Street, \#indignés! Échos d'une insurrection des consciences, París, La Découverte, 2012, p. 58.

53 A. Touraine, 2013, op. cit.; Y. Le Bot, 2013, op. cit.; Farro, 2014, op. cit.; G. Pleyers, 2010, op. cit.

${ }^{54}$ Immanuel Wallerstein, Comprendre le Monde. Introduction à l'analyse des systemes-monde, París, La Découverte, 2009. 
Los movimientos actuales rechazan el poder del dinero, de las finanzas, proponen otro tipo de desarrollo económico, otro tipo de consumo, otras formas de vida. Son en este sentido culturales.

el movimiento del 68 también era un movimiento político que abrió de cierta manera una grieta y, al mismo tiempo, rompió con un símbolo, que era el de la Revolución mexicana como el sistema perfecto, el que fundó el país y demás. Yo siento que el 132 hizo más o menos lo mismo pero con la transición mexicana: rompió con esta idea de que con la transición ya estábamos en un país perfecto, en plena democracia; que todo estaba funcionando, que todo mundo está feliz. En ese sentido yo creo que es un movimiento iconoclasta. Por eso yo diría que es, tanto político como cultural. Y lo cultural se ve más a largo plazo; sus efectos vienen después. ${ }^{55}$

Está presente la idea de que los cambios pueden no verse de inmediato en el ámbito político y social, pero que son fundamentales en tanto que transforman la conciencia de los que participan.

Claro que nuestras vidas no van a ser lo mismo [...] algo que yo aprendí mucho y que creo que fue muy valioso del 132 fue el pensar en colectivo; justamente sí es un cambio de valores al sistema individualista capitalista egoísta. Uno verdaderamente entiende lo que es el colectivo, trabajar para otras personas pero al mismo tiempo para uno mismo, es pensar distinto [...] Si algo me dejó el 132 es el cambio en mi persona y el cambio en mis relaciones con los demás. ${ }^{56}$

[...] una de las apuestas básicas del movimiento... [fue] generar politización, generar otras formas de participación, acercarnos a la gente y de ahí esta idea de crear las asambleas populares o de hacer brigadeos informativos, etc. Yo creo que siempre estuvo vigente la perspectiva de crear un cambio cultural $[\ldots]^{57}$

${ }^{55}$ Entrevista a tres estudiantes del ITAM, 27 de agosto de 2013.

${ }^{56}$ Entrevista a tres estudiantes del IтAм, 27 de agosto de 2013.

${ }^{57}$ Entrevista a estudiante del Posgrado de Ciencias Políticas de la UnAM, 30 de agosto de 2013. 
[...] a pesar de que hubo una pronta y repentina desmovilización de su parte, sabía México que contaba con un grupo de jóvenes conscientes que no volverían a ser insensibles con las causas justas de la patria, y que usando el poder mediático y una opinión que lograba llegar con facilidad la juventud, seguirían despertando conciencias y asumiendo un compromiso eterno por conseguir un país más justo. ${ }^{58}$

[...] los sujetos estamos hechos de tiempo; de memoria y olvido para ser específicos. Es así que en la palabra nos reelegimos, nos proponemos un lugar en el mundo, reorganizamos nuestra historia y nos damos un sentido. Las asambleas son el dispositivo perfecto para construir estas potencialidades. Aunque sea sutil el cambio, imperceptivo a simple vista, las asambleas han hecho cambios subjetivos en muchos de nosotros. Ya nada lo vemos igual. ${ }^{59}$

[...] No se trata de un malestar en la cultura, sino todo lo contrario; paradójicamente a través de las redes los sujetos tienen a su alcance la posibilidad de expandir deseos, placeres, descontentos, esperanzas, expectativas o pretensiones. En la red, la subjetividad se expande y la acción política puede acrecentar. ${ }^{60}$

El Movimiento por la Paz ha sido fundamental para dar un sentido a las vidas de las víctimas al permitirles salir de sus casas para compartir su duelo con otros, consolarse y llevar a cabo al mismo tiempo una acción individual (buscar justicia, a sus desaparecidos). Persiguen tanto un fin particular, aliviar su dolor y exigir justicia, al tiempo que buscan despertar la conciencia de los demás de la grave situación del país. Ambas acciones, que son una, les permiten recobrar el sentido de una vida que parece ya no tenerlo en tanto que han perdido lo más valioso. Este movimiento surge del sufrimiento, un sentimiento que unió a los miembros del MPJD y que explica su fuerza ética y su capacidad para perdurar. Tanto en los textos de Sicilia, como en la mayoría de la expresiones de las

58 Ricardo Gaitán, "La hora del artivismo", Revista Hashtag, año 1, núm. 4, mayo-junio de 2013, p. 177.

${ }^{59}$ Juan Primavera, "Precipitación a la experiencia: las asambleas", Revista Hashtag, año 1, núm. 4, mayo-junio de 2013, p. 23.

${ }^{60}$ Neftalí Granados, "1 DMx: La criminalización de la protesta”, Revista Hashtag, año 1, núm. 4, mayo-junio de 2013, p. 55. 
víctimas, se habla de cómo el movimiento les ha permitido salir de la soledad de su sufrimiento para compartirlo y consolarse mutuamente; que en lugar de quedarse a llorar en sus casas, el asistir a reuniones y a manifestaciones les ha devuelto un sentido a sus vidas. Muchos miembros del movimiento han dejado su trabajo y familia de lado, gastan sus pocos ingresos para asistir, a veces desde muy lejos, a las reuniones semanales y participar en las caravanas. ${ }^{61}$ Paradójica y trágicamente, demandan en democracia aquello que se exigía durante y después de los regímenes militares en el Cono Sur: conocer el paradero de los desaparecidos, el conocimiento preciso de la forma en la que murieron las víctimas, donde están sus cuerpos. Esto al tiempo que es un movimiento cultural que vehicula una enseñanza ética y política que percibe otra forma de ver las relaciones sociales y políticas:

dar voz a las víctimas porque las humaniza y coloca el tema en el debate público. También porque genera un cuestionamiento al gobierno y a la propia sociedad y logra, desde el aporte ético de la no violencia, conmover al país y dar testimonio del dolor. Ayuda a dar voz a las víctimas que no la tienen, que no tienen contactos, especialmente a las más pobres [...] [además] tiene un pedagogía ciudadana que apuesta al diálogo, a la inclusión, en un país en el que el diálogo no es una práctica. Se apuesta al diálogo desde la ética y en defensa del Estado democrático de derecho. ${ }^{62}$

Por otro lado, hace emerger un nuevo actor social que pugna por poner en el centro de la demanda por mayor seguridad al sujeto, a la persona:

[...] Hacía falta, además, un espacio conformado sólo por víctimas donde pudieran hablar con aquellos que no sólo entendían y se solidarizaban con lo que sentían, sino que lo vivían en carne propia, un

${ }^{61}$ Con base en las entrevistas hechas por Ivonne G. Villalón (ITAM) y Pascale Naveau (Universidad Católica de Lovaina).

${ }^{62}$ Elena Azaola, "El movimiento por la Paz con Justicia y Dignidad", Desacatos, núm. 40, septiembre-diciembre de 2012. 
espacio donde se entendiera las razones de su urgencia, pero no en forma de una terapia colectiva, pues muy pronto se cansaron de hablarse una y otra vez sobre su situación personal y casos, sino un ejercicio de diálogo y acuerdo sobre el cual pudiera expresarse una voz representativa y unificada de la postura y visión que tienen sobre la dirección y necesidades a las cuales debe encauzar sus esfuerzos el Movimiento. Con ello hemos sido testigos del nacimiento de un nuevo sujeto social. ${ }^{63}$

Finalmente, el hecho de que este movimiento se concentre en el sujeto humano y en sus sentimientos explica que traduzca su expresividad de diversas maneras: por medio de testimonios y expresiones artísticas de todo tipo. ${ }^{64}$

\section{Conclusiones}

En este artículo nos hemos concentrado menos en los logros concretos de los principales movimientos sociales contemporáneos en México: la descripción de sus estrategias, de su capacidad de acción; a la que se enfoca la sociología de movilización de recursos, ${ }^{65}$ y más sobre su significado. Y, en esta medida parece paradójico que la tragedia que significó el sexenio de Calderón en lo que se refiere al costo humano de "la guerra contra las drogas", haya producido dos movimientos tan plenos de sentido. De la misma manera como el movimiento del EzLN modificó la visión del resto de los mexicanos sobre los indígenas, el Movimiento por la Paz con Justicia y Dignidad modificó la forma como la sociedad mexicana (y en parte el sistema político) percibía la situación de inseguridad y de violencia y los resultados de la "guerra contra las drogas". El movimiento \#YoSoy132 no sólo puso al descubierto los costos políticos

63 Alberto M. Solís Castro, "Corazón de movimiento", Brújula Ciudadana, núm. 34, junio de 2012.

${ }^{64}$ Geoffrey Pleyers y Pascale Naveau, "Espace de la violence et mouvement pour la paix au Mexique”, manuscrito, EHess, París, 2012.

65 A pesar de que el \#YoSoy132 no consiguió frenar el regreso del PRI, como se lo proponía un sector de éste, el MPJD logró la importantísima Ley de Víctimas. 
del poder de los medios de comunicación, sino que enfatizó la manera en la cual los medios de comunicación en nuestro país (y de hecho en el mundo) generan nuestra representación (como dicen Habermas y Marcel Gauchet) del mundo político, económico, social y subjetivo, por decirlo de otra manera de los valores.

El Movimiento por la Paz dio sentido a la vida de los que habían perdido a un ser querido o que lo estaban buscando. Además, invirtió el paradigma de las demandas sociales que había dominado las grandes movilizaciones de mediados de la década de 2000 que exigían una acción estatal más firme para contrarrestar la ola de inseguridad, para centrar su atención sobre la tragedia humana, sobre las víctimas. Este movimiento rechazó una guerra "que oficialmente no existe" 66 y que hablaba sólo de estadísticas de narcotraficantes, soldados y daños colaterales en una lógica exclusivamente de guerra, sin mencionar a las víctimas, su sufrimiento y a la explosión de violencia que esta estrategia implicaba. El MPJD transmuta este relato en uno que habla sobre la tragedia humana e impone la demanda ética de reconocer que en cada hecho existen personas con una historia, una realidad, una familia, y que exige investigar para conocer precisamente cómo murió cada persona y para lograr presentar con vida al familiar desaparecido. La forma oficial de representar la guerra en contra del narco implicaba, además, una doble victimización de los que habían perdido a alguien, porque criminalizaba a las víctimas, ${ }^{67}$ las que lejos de ser

${ }^{66}$ MPJD, Documento del Movimiento por la Paz con Justicia y Dignidad, Jenaro Villamil, Documento del Movimiento por la Paz con Justicia y Dignidad [en línea], México, 11 de junio de 2011, http://jenarovillamil.wordpress.com/2011/06/11/ documento-del-movimiento-por-la-paz-con-justicia-y-dignidad/

${ }^{67}$ La criminalización lleva a que sean doblemente víctimas, una por haber perdido a un ser querido y la otra porque la sociedad que los rodea los margina. Esta situación se ha producido por una criminalización que se ha dado desde arriba, desde el poder: recuérdese las innumerables veces que las autoridades declararon que una matanza de jóvenes (por ejemplo la de Balcárcel) se había producido porque estaban metidos en algo, sin siquiera haber hecho una investigación. También se producía desde abajo, por una especie de internalización del discurso del poder. Muchos familiares de las víctimas han sido marginados e incluso han tenido que migrar porque la gente se ha alejado de ellos por temor a que, en efecto, estuvieran involucrados en algo ilegal. 
consideradas como tales, se las suponía involucradas en el narcotráfico, sin que mediara ninguna investigación. Esto llevaba a que sus vecinos y familiares se alejaran de ellos por miedo o rechazo.

Mientras que el movimiento de las víctimas de la violencia se enfrentaba a los efectos de una desastrosa política de seguridad, el movimiento \#YoSoy132 no sólo puso en duda la idea de la popularidad sin falla del candidato del PRI y de la inevitabilidad de su triunfo electoral, sino que impugnó los valores políticos y culturales que propagan los medios de comunicación masiva. No sólo se pronunciaba en contra del obvio acuerdo entre el PRI y los medios de comunicación, sino principalmente de la forma en la que los medios conforman nuestras conciencias, nuestras formas de consumo, nuestros valores.

Estos dos movimientos representan las dos caras de la sociedad de nuestro país en el momento actual: la cara orientada hacia el futuro, la de los jóvenes que exigen un mejor porvenir, un mejor país, una mejor democracia y la cara trágica, de los que lo han perdido todo en la persona de algún ser amado, que ha sido asesinado o secuestrado, y que se aferran a la lucha porque las víctimas sean reconocidas como tales y para intentar dar sentido a sus propias vidas.

De esta manera, se anuncian los dos movimientos del sexenio actual. Mientras que el MPJD resiste, a pesar del velo que el nuevo gobierno ha tratado de imponer a esa guerra que "nunca existió" y que ha sido desenmascarado con los sucesos de Iguala y la desaparición de los 43 estudiantes de la normal de Ayotzinapa, el movimiento de jóvenes \#YoSoy132 parece haberse agotado, en parte porque un sector del movimiento se comprometió demasiado en contra de la candidatura de Peña Nieto, con lo que, a su triunfo, agudizó las diferencias que siempre habían existido entre apartidistas y partidistas, radicales y moderados, entre otras identidades, con lo que dio paso a la desorganización y al desánimo. ${ }^{68}$

Pero el desgaste es una característica de todos los movimientos sociales que no se institucionalizan y que de facto dejan de ser

68 Marco Estrada Saavedra, "Sistema de protesta: política, medios y el \#YoSoy 132”, Sociológica, vol. 29, núm. 82, mayo-agosto de 2014, pp. 108-111. 
movimientos cuando lo hacen. Ni una ni la otra circunstancia les restan algo de su significado, como no se lo ha restado a estos dos movimientos. Al igual que en todos los movimientos sociales importantes, algo queda, como dice Wallerstein: ${ }^{69}$ dejan un legado. Quizá, uno de los más significativos es que frente a una creciente integración con el Norte, con estos dos movimientos sociales, así como con lo fue con el EzLN, México se integra a los movimientos sociales de América Latina, pero, más importante aún, a la ola de movimientos globales.

\section{BibLIOGRAFÍA}

Alcántara, Max, "Las antorchas que escupían enojo e irradiaban esperanza”, Revista Hashtag, año 1, núm. 4, mayo-junio de 2013, p. 31.

Alonso, Jorge, "Cómo escapar de la cárcel de lo electoral: el Movimiento \#YoSoy132", Desacatos, núm. 42, mayo-agosto de 2013, pp. 17-40.

Arato, Andrew, Civil Society, Constitution, and Legitimacy, Lanham, Maryland, Rowman and Littlefield Publishers, 2000.

Azaola, Elena, "El movimiento por la Paz con Justicia y Dignidad", Desacatos, núm. 40, septiembre-diciembre de 2012.

Aziz, Alberto, "Acción Nacional: el partido en el poder, 2000-2006", en Ilán Bizberg, México ante el espejo latinoamericano, México, El Colegio de México- Fundación Konrad Adenauer (KAs), 2010.

Bensusán, Graciela y Kevin Middlebrook, Sindicatos y política en México: cambios, continuidades y contradicciones, México, Flacso México-Uam Xochimilco, 2013.

Bizberg, Ilán, El Estado y el sindicalismo en México, México, El Colegio de México, 1982.

-, "La democracia vacía”, en Ilán Bizberg y Francisco Zapata, Los grandes problemas de México, vol. 6: Los movimientos sociales, México, El Colegio de México, 2010.

, "Civic Society, Democratization, and Globalization in Latin

${ }^{69}$ Immanuel Wallerstein, "Levantamientos aquí, allá, y en todas partes", $L a$ Jornada, 6 de julio de 2013, en http://www.jornada.unam.mx/2013/07/06/ opinion/021a1mun 
America”, en Antimo L. Farro y Henri Lustiger-Thaler (eds.), Reimagining Social Movements: From Collectives to Individuals, Surrey, Ashgate, 2014.

-(coord.), Las variedades del capitalismo en América Latina, El Colegio de México (en prensa).

Concha Malo, Padre Miguel, citado por Paulina Candia y Marta Molina, "Queremos paz, justicia y dignidad: el jya basta! de un movimiento global”, Brujula Ciudadana, 2012, pp. 40-41.

Estrada Saavedra, Marco, "Sistema de protesta: política, medios y el \#YoSoy 132”, Sociológica, vol. 29, núm. 82, mayo-agosto de 2014, pp. 83-123. Farro, Antimo Luigi, “A New Era for Collective Movements: The Subjectivization of Collective Action", en Antimo L. Farro y Henri Lustiger-Thaler (eds.), Reimagining Social Movements: From Collectives to Individuals, Surrey, Ashgate, 2014.

Gaitán, Ricardo, "La hora del artivismo", Revista Hashtag, año 1, núm. 4, mayo-junio de 2013, p. 177.

Gall, Olivia, "Identidad, exclusión y racismo: reflexiones teóricas y sobre México", Revista Mexicana de Sociología, año 66, núm. 2, abril-junio de 2004, http:/ /www.ejournal.unam.mx/rms/2004-2/RMS04201.pdf

Garretón, Manuel Antonio et al., "Movimiento social, nuevas formas de hacer política y enclaves autoritarios. Los debates del Consejo Asesor para la Educación en el gobierno de Michelle Bachelet en Chile", Polis, núm. 30, 2009.

Giovanopoulos, Christos, "La démocratie es née dans les places", Revista Contretemps (ed.), D’Athènes à Wall Street, \#indignés! Échos d'une insurrection des consciences, París, La Découverte, 2012, pp. 83-84.

Graeber, David, "Faire l'impossible. À propos de la décision au consensus”, Revista Contretemps (ed.), D’Athènes à Wall Street, \#indignés! Échos d'une insurrection des consciences, París, La Découverte, 2012, pp. 97-100.

Granados, Neftalí, “1 DMx: La criminalización de la protesta”, Revista Hashtag, año 1, núm. 4, mayo-junio de 2013, p. 55.

González Villareal, Roberto, El Acontecimiento \#YoSoy132. Crónica de la Multitud, México, Terracota, 2010.

Hardt, Michael y Toni Negri, "Le combat pour la 'démocratie réelle'”, Revista Contretemps (ed.), D’Athènes à Wall Street, \#indignés! Échos d'une insurrection des consciences, París, Éditions la Découverte, 2012, p. 80. 
Le Bot, Yvon, "De la révolution à la mondialisation. Changement de paradigme en Amérique latine", Socio, núm. 2, "Révolutions, contestations, indignations", París, Éditions de la Maison des Sciences de l'Homme, 2013.

y Subcomandante Marcos, Le rêve zapatiste, París, Éditions du Seuil, 1997.

Molzahn, Cory, Octavio Rodríguez Ferreira y David A. Shirk, Drug Violence in Mexico Data and Analysis Through 2012, Trans-Border Institute, University of San Diego, 2013, http://justiceinmexico.files.wordpress. com/2013/02/130206-dvm-2013-final.pdf

Muñoz Ramírez, Gloria, \#YoSoy 132 Voces del Movimiento, México, Ediciones Bola de Cristal, 2013.

MPJD, Documento del Movimiento por la Paz con Justicia y Dignidad, Jenaro Villamil, Documento del Movimiento por la Paz con Justicia y Dignidad [en línea], México, 11 de junio de 2011, http://jenarovillamil. wordpress.com/2011/06/11/documento-del-movimiento-por-lapaz-con-justicia-y-dignidad/

Occupy Wall Street, Declaración de la Ocupación de Wall Street, Revista Contretemps (ed.), D'Athènes à Wall Street, \#indignés! Échos d'une insurrection des consciences, París, Éditions la Découverte, 2012, p. 73.

O'Donnell, Guillermo, "Horizontal Accountability in New Democracies", Journal of Democracy (Baltimore, The Jonhs Hopkins University Press), vol. 9, núm. 3, 1998.

Palacios Canudas, Ana Elda, "\#YoSoy132: desarrollo y permanencia: perspectivas desde la zona metropolitana”, tesis de Maestría en ciencia política, México, El Colegio de México, agosto de 2013.

Pérez, Nahum, "El mitin de la estela de luz: \#YoSoy132 se masifica", Revista Hashtag, año 1, núm. 4, mayo-junio de 2013, p.16.

Pleyers, Geoffrey, Alter-globalization: Becoming an Actor in the Global Age, Cambridge, Polity Press, 2010.

- y Pascale Naveau, "Espace de la violence et mouvement pour la paix au Mexique", manuscrito, EHess, París, 2012.

Primavera, Juan, "Precipitación a la experiencia: las asambleas", Revista Hashtag, año 1, núm. 4, mayo-junio de 2013, p. 23.

Propuestas de la Asamblea General de Puerta del Sol, en Revista Contretemps (ed.), D'Athènes à Wall Street, \#indignés! Échos d'une insurrection des consciences, París, La Découverte, 2012, p. 58. 
Revista Hashtag, año 1, núm. 4, mayo-junio de 2013, varias páginas.

Sen, Amartya, L'économie est une science morale, París, La Découverte, 2003.

Sicilia, Javier, "Las víctimas", Proceso, 31 de marzo de 2014 en http://movimientoporlapaz.mx/articulos-y-reportajes/

—_ "Políticas públicas para construir la Paz. Texto leído a los y la candidata a la Presidencia en los Diálogos por la Paz", 28 de mayo de 2012, http://movimientoporlapaz.mx/es/2012/05/29/politicas-publicas-para-construir-la-paz-texto-leido-a-los-y-la-candidata-a-la-presidencia-en-los-dialogos-por-la-paz/

—_, "Seguimos hasta la madre", Brújula Ciudadana, núm. 34, junio de 2012.

Silva, Eduardo, Challenging Neoliberalism in Latin America, Cambridge, Cambridge University Press, 2009.

Smulovitz, Catalina, "Organizaciones que invocan derechos, sociedad civil y representación en la Argentina”, en Bernardo Sorj y Darcy de Oliveira, Sociedad civil y democracia en América Latina: crisis y reinvención de la política, Río de Janeiro, Ediciones Centro Edelstein, 2007, pp. 13-62.

Socio, núm. 2, "Révolutions, contestations, indignations", París, Éditions de la Maison des sciences de l'homme, 16 de diciembre de 2013.

Solís Castro, Alberto M., "Corazón de movimiento", Brújula Ciudadana, núm. 34, junio de 2012.

Tilly, Charles, From Mobilization to Revolution, Nueva York, Random House, 1978.

Touraine, Alain, La Fin des Sociétés, París, Seuil, 2013.

— L L L Production de la Société, París, Seuil, 1973.

—, La Voix et le Regard: sociologie des mouvements sociaux, París, Éditions du Seuil, 1978.

— François Dubet, Michel Wieviorka y Jan Strzelecki, Solidarité, París, Fayard, 1982.

Wallerstein, Immanuel, Comprendre le Monde. Introduction à l'analyse des systemes-monde, París, La Découverte, 2009.

"Levantamientos aquí, allá, y en todas partes", La Jornada, 6 de julio de 2013, en http://www.jornada.unam.mx/2013/07/06/opi nion/021a1mun

\#YoSoy132, "Principios generales del movimiento", 26 de junio de 2012, en http:/ /www.yosoy132media.org/yosoy132oficial/principios-generales-del-movimiento/ 
Zapata, Francisco, El sindicalismo Latinoamericano, México, El Colegio de México, 2013.

\section{Entrevistas}

Emilio Álvarez Icaza, julio de 2013 (Ilán Bizberg, Pascale Naveau e Ivonne Villalón).

Estudiante de comunicación en la FCPys, UNAM y estudiante en la Barra Nacional de Abogados, agosto de 2013 (Ilán Bizberg e Ivonne Villalón).

Miembro de la mesa de trabajo sobre democratización de los medios de comunicación del \#YoSoy132, julio de 2013 (Ivonne Villalón).

Estudiante de la Maestría en Antropología en la Universidad Iberoamericana, 22 de agosto de 2013 (Ivonne Villalón).

Tres estudiantes del IтAм, 27 de agosto de 2013 (Ilán Bizberg, e Ivonne Villalón).

Estudiante del posgrado en Ciencias Política de la unam, 30 de agosto de 2013 (Ivonne Villalón). 